minutes. Silver present, 0.2600 gram; aluminum, 0.2500 gram, silver found, $0.2600,0.2599$ and 0.2600 gram. The deposits obtained in this electrolyte were very poor. The addition of ammonium nitrate helped matters but little. Great care was necessary in washing not to lose some of the deposit.

With the conditions given for the separation of silver from aluminum, the former was quantitatively separated from cadmium, chromium, cobalt, iron, lead, magnesium, manganese, nickel and zinc.

It was also tried to effect the separation of silver from a number of other metals in a potassium cyanide electrolyte. No success was attained. The successful separations with mercury were those with aluminum and magnesium. Failures resulted in the case of iron, nickel, cobalt, zinc, manganese and cadmitum. The electrolytes tried were sulphuric acid and nitric acid. Other separations are in progress.

\title{
ON THE STRUCTURE OF ALLOYS. PART I. ALUMINIUM ALLOYS. ${ }^{1}$
}

BY WILLIAM CAMPBELI.

Receired June 30,1904 .

THE AILOYS OF COPPER AND ALUMINIUM.

Previous Investigations.-Richards ${ }^{2}$ describes the color of these alloys and gives the melting-points as determined by Le Verrier. He states that the natural compounds of aluminium and copper are those with the formulas $\mathrm{AlCu}_{3}$ and $\mathrm{Al}_{2} \mathrm{Cu}_{3}$, and goes on to describe them. He says that the sharp fall in the melting-point at 37.5 per cent. aluminium indicates the alloy $\mathrm{Al}_{3} \mathrm{Cu}_{2}$, and remarks that it is a singular fact that the addition of copper to aluminium, in amounts up to Io per cent., lowers the melting-point of the latter about $4^{\circ}$ for every per cent. of copper present.

If the figures given by Le Verrier be plotted, we have a curve showing a drop to a minimum from pure copper to the 7.5 per cent. aluminium alloy, followed by a rise to a summit at the ro per cent. alloy, then a sudden drop (with two slight halts) from this point at

1 Read before the New York Section of the American Chemical Society, January 8 , I904.

2 "Aluminum," p. 535, et seq ( 1896 ed.). 
I029 ${ }^{\circ} \mathrm{C}$. to the 62.5 per cent. copper alloy at $545^{\circ} \mathrm{C}$. Then follows a slight rise to $553^{\circ} \mathrm{C}$. at 50 per cent. copper followed by a regular fall to $527^{\circ} \mathrm{C}$. at the 33 per cent. alloy. Now, if we omit the reading of $528^{\circ} \mathrm{C}$. as that of the 20 per cent. alloy, for it is certainly incorrect, the rest of the curve consists of a rise to aluminium. In other words, the curve consists of two summits at 50 per cent. and 90 per cent. copper, and three minima at 33 per cent., 62.5 per cent., and 92.5 per cent. copper, and the natural explanation would be that the summits represent compounds, the minima eutectics. So, if the 50 per cent. alloy represents a compound and the 33 per cent. copper alloy were the eutectic of that compound and aluminium, we should naturally suppose that the curve from aluminium to the 33 per cent. copper alloy would show a fall for each addition of copper, just as the freezing-point of water is lowered progressively with each addition of salt, until at $-22^{\circ} \mathrm{C}$. we reach the eutectic point, with 23.5 per cent. of sodium chloride. There is apparently no conclusive reason why the two alloys corresponding to $\mathrm{Al}_{3} \mathrm{Cu}_{2}$ and $\mathrm{Al}_{2} \mathrm{Cu}_{3}$ should be taken as definite compounds.

Le Chat lier, in a paper on the "Fusibility of Metallic Alloys," 1 gives the freezing-point curve of the series, which is very smooth and regular. It shows two maxima, the one at 50 per cent. copper (or about 30 per cent. in equivalents), the other at 88 per cent. copper (or 75 per cent. in equivalents), and three minima, at 33 per cent. copper (or abont i 8 per cent. equivalents), at 54.5 per cent. copper (or 34 per cent. equivalents) and at 90.5 per cent. copper (or 80 per cent. equivalents). He concludes that two definite compounds are indicated, viz., $\mathrm{Al}_{2} \mathrm{Cu}$ (54 per cent. copper) and $\mathrm{AlCu}_{3}$ ( 87.6 per cent. copper), which places the first almost at the minimum point at 54.5 per cent. copper. He says that these results agree with the previous determinations of $\mathrm{Le}$ Verrier. ${ }^{2}$ They contradict the conclusions at which he had arrived from a chemical study of the alloys, ${ }^{3}$ when he had isolated something corresponding to $\mathrm{AlCu}$ by hydrochloric acid or potassium hydroxide from an alloy with an excess of aluminium. These crystals were certainly altered by the reagents used. The formation of two compounds gives rise to three eutectics.

1 Bull. de la Sac. d'Enc., 1895, p. 569.

- Lejeal : l'Aluminium, p. I68.

3 "On Definite Compounds in Metaltic Alloys," Compt. Rend., 120, p. 835. 
In a paper on the "Dilatation of Metallic Alloys," Le Chatelier ${ }^{1}$ explains why the maximum points of the curves of fusibility do not always correspond exactly to a composition of the melted portion identical to the composition of definite chemical compounds to which these maximum points are supposed to owe their existence. Van der Waals" verified Le Chatelier's results and based his reasoning on the chemical equilibriums of W. Gibbs, which show that, to each maximum point of a curve of fusibility; there must necessarily correspond a composition of the liquid portion identical to that of the solid portion falling ont of solution. This contradiction between theory and experience disappears if, starting from the definite compound, we consider the solicl portion to constitute a solid solution.

When an alloy is made up by the juxtaposition in variable proportion of two well-defined constituents, a metal and a combination for instance, the dilatation of the alloy will necessarily be intermediate between those of the two components; if, on the contrary, the dilatation of the alloy has a very different value, it may be inferred that the alloy is a solid solution.

In the case of the alloys of aluminium and copper the compound $\mathrm{AlCu}$ is quite normal, both as regards fusibility and dilatation curves. The compound $\mathrm{Al}, \mathrm{Cu}$ exhibits a maximum meltingpoint corresponding to 30 per cent. copper in equivalents differing from that of the definite compound, 33 per cent. The dilatation curve exhibits between these two percentages a very steep fall, which seems to indicate the existence of a solid solution.

In a former paper on the "Alloys of Aluminium'"s a freezingpoint curve was given very similar to that of Le Chatelier, but containing many lower points in addition. The maximum in the neighborhood of 50 per cent. copper was thought to indicate the compound $\mathrm{Al}_{5} \mathrm{Cul}_{1}$, but the results of mictoscopic research seem to show that this is not the case. The microscope shows that the horizontal line denoting the eutectic should be continued on to about 2 per cent. copper.

The microstructure of the copper-aluminium alloys has been studied by Le Chatelier ${ }^{4}$ by means of a diffusion alloy. Five p. 334

1 Compt. Rend., June, I8g9; Bull. de la Soc. d'Enc., 1899, p. 900 ; Metallographist. 2,

2 Archives des Sciences néeriandaises, 1899.

3 W. Campbell and J. A. Mathews: This Journal, 24, 265.

4 Metallographist, 4, p. I8. 
distinct zones were seen. At the top are found grains and dendrites of aluminium passing down into the entectic. When they disappear, well-defined crystals of $\mathrm{Al}_{2} \mathrm{Cu}$ appear and the eutectic gradually diminishes until the whole mass is homogeneous. Below this, crystals, probably of $\mathrm{AlCu}$, come in and are surrounded by a ground-mass of $\mathrm{Al}_{2} \mathrm{Cu}$. Then follow similar crystals in a eutectic alloy of minute structure. When these disappear, crystals of $\mathrm{AlCu}_{3}$ come in and are seen surrounded by the eutectic.

Léon Guillet ${ }^{1}$ prepared a series of alloys by reducing pure copper oxide with metallic altuminitum. By dissolving out the groundmass with hydrochloric acid he obtained crystals of $\mathrm{AlCu}_{3}$ (87.I I to 87.75 per cent. copper, and $\mathrm{AlCu}$ (69.3 to 69.8 per cent. copper). The compound $\mathrm{Al}_{2} \mathrm{C}_{11}$ was isolated by nitric acid and analyzed, 53.85 and 53.7 per cent. copper. In theory these three compounds require $87.55,70.13$ and 54 per cent. copper. He found that the compound $\mathrm{AlCu}$ contained 2 to 3 per cent. of residue, insoluble in concentrated nitric acid. It proved to be a compound of silicon, copper and aluminium.

Microscopic Examination. -The series lying between $O$ and 52 per cent. copper presents no great difficulty. The freezingpoint curve is made up of two inclined branches: The one starts from pure aluminium, showing an average fall of $3.75^{\circ} \mathrm{C}$. for every per cent. of copper added; the other starts from the maximum at about 50 per cent. copper at $580^{\circ} \mathrm{C}$., showing an average fall of almost $2.5^{\circ} \mathrm{C}$. for every per cent. of copper decreased. These two branches meet at $535^{\circ} \mathrm{C}$. at about 32 per cent. copper, and through this point the horizontal line, denoting the solidification of the eutectic, runs from about 2 to about 50 per cent. copper. Thus, between o and 32 per cent. copper the alloys consist of two constituents: The one is aluminium, which freezes out when the temperature of the alloy reaches that of the inclined branch, or "liquidus" curve, and continues to separate out, thus enriching the mother-liquor in copper until at $535^{\circ} \mathrm{C}$. the latter contains 32 per cent. copper, when it freezes as the etrtectic, the second constituent, whose solidification produces the evolution of heat marked by the horizontal line through $535^{\circ} \mathrm{C}$.; or the "solidus" curve.

Between 52 per cent. and 32 per cent. copper the alloys consist of two constituents; the compound $\mathrm{Al}_{2} \mathrm{Cu}$ which freezes out when

I Bull. de la Soc. d'Enc., a, 236 (1902). 
the temperature reaches the "liquidus" and enriches the motherliquor in aluminum until it has the composition of the eutectic, namely, about 32 per cent. copper. This occurs at $535^{\circ} \mathrm{C}$. as before, when the whole mass becomes solid, the solidification of this eutectic or ground-mass (the second constituent) being denoted by the horizontal line through $535^{\circ} \mathrm{C}$, or the "solidus," Hence, from aluminium to the entectic point we find the alloys consist of grains and dendrites of aluminitum in an increasing eutectic. At .32 per cent. copper the alloy consists of the eutectic alone, and we have neither free aluminium nor the free compound, simply a fine mixture of flakes of aluminitum and flakes of the compound. From the eutectic point to 52 per cent. copper we find crystals of the compound in a decreasing ground-mass of the eutectic. So we find in this region of the series only two phasesaluminium and the compound $\mathrm{Al}_{2} \mathrm{Cu}$.

\section{DESCRIPIION OF SPECIFIC ALIOYS.}

2.28 per cent. $\mathrm{Cu}, 97.72$ per cent. Al. Hard and strong. Cuts well with sharp tool, but not with saw. Composed of well-packed grains of aluminium with discontinuous ground-mass. The latter is composite in only a few places; generally consists of $\mathrm{CuAl}_{2}$ alone. A similar case is found in annealed low-carbon steel where the pearlite has become patches of cementite, due to the absorption of its ferrite by the neighboring ferrite srains. Best etching with potassium hydroxicle or hydrochloric acil. Deep etching shows up boundaries of aluminium grains, also attacks their centers. Aluminium grains apparently contain some $\mathrm{CuAl}_{2}$ in solid solution. Fig. I 3 shows the slowly cooled alloy $\times 33$ diam. etched with potassium hydroxide.

4.45 per cent. $\mathrm{Cu}, 95.55$ per cent. A1. Hard and strong. Cuts better with the saw, but begins to cut with a gritty feel. Shows the same structure as the above, but the aluminium grains are more inclined to form dendrites; are larger, ground-mass continuous for the most part and resembles a coarse eutectic, but is not typical. Etching attacks aluminitum of the eutectic most deeply, due probably to couple action.

Alloys containing 6.5 per cent. and 8.2 per cent. copper are similar to the above. The dendritic character of the aluminium and the amount of ground-mass, or entectic increase with the copper presert. In the 8.2 per cent. copper alloy the eutectic approaches more nearly normal, though much free $\mathrm{Al}_{2} \mathrm{Cu}$ is still seen; the alloy inclines to brittleness, cuts with a gritty feel, yet saws fairly well. The difference between the alloys un to say 9 per cent. copper is not marked, and lies in the structure and amount of the ground-mass, and in the etching of the grains and dendrites of aluminium. 
12.5 per cent. $\mathrm{Cu}, 87.5$ per cent. Al. Hard and tough. Cuts very gritty. Very easily cut with saw. Fracture of ingot is finely granular, inclined to be fibrous. Slowly cooled it is more coarsely granular, resembling the structure of impure aluminium. On etching with dilute nitric acid, irregular grains and dendrites are seen in a continuous matrix. Ground-mass contains more of the compound than the typical 32 per cent. alloy, due to absorption of some aluminium by the dendrites. The slowly cooled alloy is seen in Fig. I, magnified 35 diameters vertical illumination ( $X 35$ v.). With increase in copper the alloys become harder, more gritty to cut and the fracture of the ingot becomes finer. With about I9 per cent. copper the ingot is strong, rings well, fracture is fine, dull and granular inclined to be fibrous, while the surface is covered with beautiful dendrites of aluminium, which are only about $1 / 10$ the size of those ordinarily found on the surface of an ingot of the pure metal.

23.8 per cent. $\mathrm{Cu}, 76.2$ per cent. Al. Much weaker than the above; fracture is finer. A section shows well marked dendrites, some very large, set in the typical eutectic. In the cast alloy the fracture appears to have become coarser, because the dendrites of aluminium are now producing the regular ingot structure, due to growth perpendicular to the cooling surfaces ( $c f$. fracture of cast zinc, antimony, etc.). Relative amount of eutectic seems less than in the slowly cooled alloy. Fig. 2, $\times 33$ v., shows the slowly cooled alloy, etched with dilute nitric acid.

32 per cent. $\mathrm{Cu}, 68$ per cent. Al. Fracture shows very large plate-like surfaces, while cavities show very good prisms with parallel growth, and faces covered with very small rounded knobs. Fracture fine, showing ingot structure very well, while on the surface is a well-marked hexagonal network of dendrites, especially along medial lines. The slowly cooled alloy shows the typical eutectic structure, together with fine black lines, along which fracture occurs, producing plate-like surfaces. A vertical section of the cast alloy shows a very curious dendritic growth of the compound more or less perpendicular to the cooling faces of the mold. This only extends for a short distance into the alloy and is apparently part of the eutectic, for under a high power it is seen that the structure is in places composed of parallel prisms, but each prism is composite ( $i$.e., is composed of $\mathrm{Al}$ and $\mathrm{Al}_{2} \mathrm{C} . u$ ) These will be mentioned again later. Fig. 3, $\times 35$, obliquely illuminated $(X 35$ o.) shows the slowly cooled alloy; has a granular appearance, due to variation from fine to coarse, but where the aluminium is coarse the compound is coarse, for when a coarse granule of aluminium solidified a similar flake or granule of the compound solidified simultaneously alongside, that the composition of both the liquid and the solid might remain constant and equilibrium might be maintained. 
A further increase in copper brings in the compound $\mathrm{Al}_{2} \mathrm{Cu}$, which has been isolated by Le Chatelier. The compound increases with the copper present, forming first isolated rods and prisms, then well-defined prisms, showing marked parallel growth until at 52 per cent. copper the whole mass becomes homogeneous. As the compound in theory requires 54 per cent. copper, the difference must be due to aluminium in solid solution. Le Chatelier's explanation of the $5 \dot{f}$ per cent. alloy melting at a lower temperature than that with, say, 4 per cent. less copper (in other words, the freezing of $\mathrm{Al}_{2} \mathrm{C}_{11}$ at a point near a minimum of a curve) being due to the formation of solid solutions may be correct, but some recent experiments seem to indicate that the depression at 54 per cent. copper was due to surfusion, for all our readings were taken without stirring. If that be so, then the curve would rise uniformly from 32 per cent. to 54 per cent., then would take a sharp rise to 90 per cent. copper and there would be no depression at 54 per cent. This would give a curve much more easily explained. It is proposed to take a new series of pyrometric readings in this series.

37 per cent. Cu, 63 per cent. Al. Hard and brittle. Cuts well with a saw. The fracture shows a fine bright crystalline structure quite different from those alloys between o and, 32 per cent. copper. Cavities are lined with beautiful prismatic and needle-like crystals, with marked parallel growth. A section etched with dilute nitric acicl shows crystals of the compound, black to purple, with distinct orientation, or larger, more isolated prisms, set in the eutectic. The latter varies from fine to coarse, and in places is seen in the form of distinct prisms, usually round a cavity. The compound is often surrouncled by an envelope of aluminium (cf., slowly cooled CuAg alloys). When cast, the fracture shows good ingot structure, built up of similarly orientated dendrites of the compound, while the surface is covered with a network of clendrites similar to those met with in alloys of tin and antimony, containing: about Io per cent. tin. In section the ingot shows very beautiful designs, due to the marked geometrical orientation of the dendrites of the compound. Fig. I 4, $\times 33$ v., shows this alloy. The compound is seen as sections of crystals, which etch black and which occur in long trains with definite orientation. In Fig. Is are seen several isolated prisms. The entectic in places shows a distinctly dendritic structure. Fig. In shows a vertical section of the cast alloy, in which can be seen the dendrites of the compound in long, parallel trains. In each case etching was with dilute nitric acicl.

44 per cent. $\mathrm{Cu}, 56$ per cent. A1. Brittle, coarsely crystalline with cavities lined with prismatic needles in parallel growth. Are larger than in the last alloy. In sections very perfect crystals of the compound are seen; grow in grouns of similarly orientated prisms. Are best seen under oblique illumination. The 

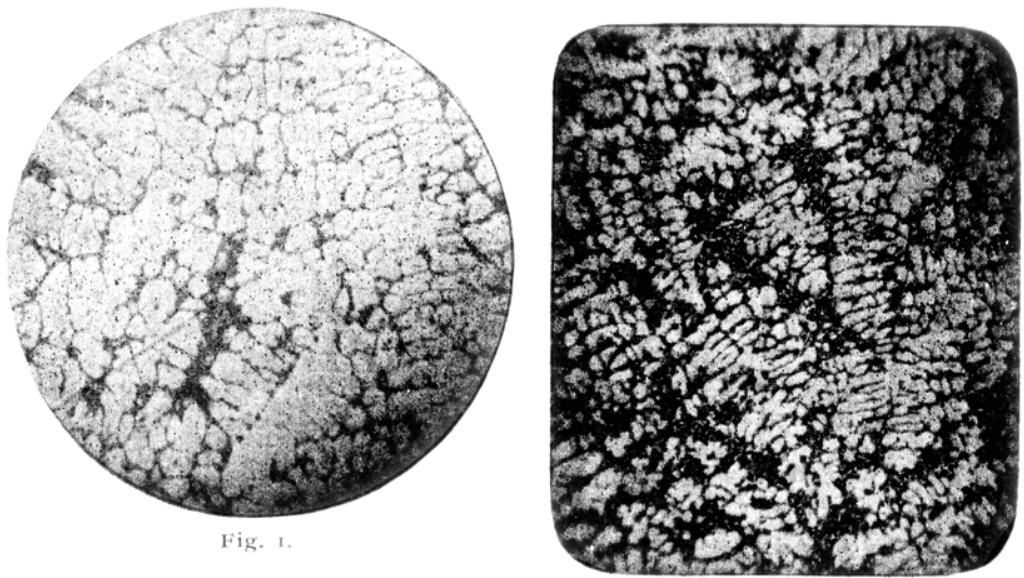

Fig. 2
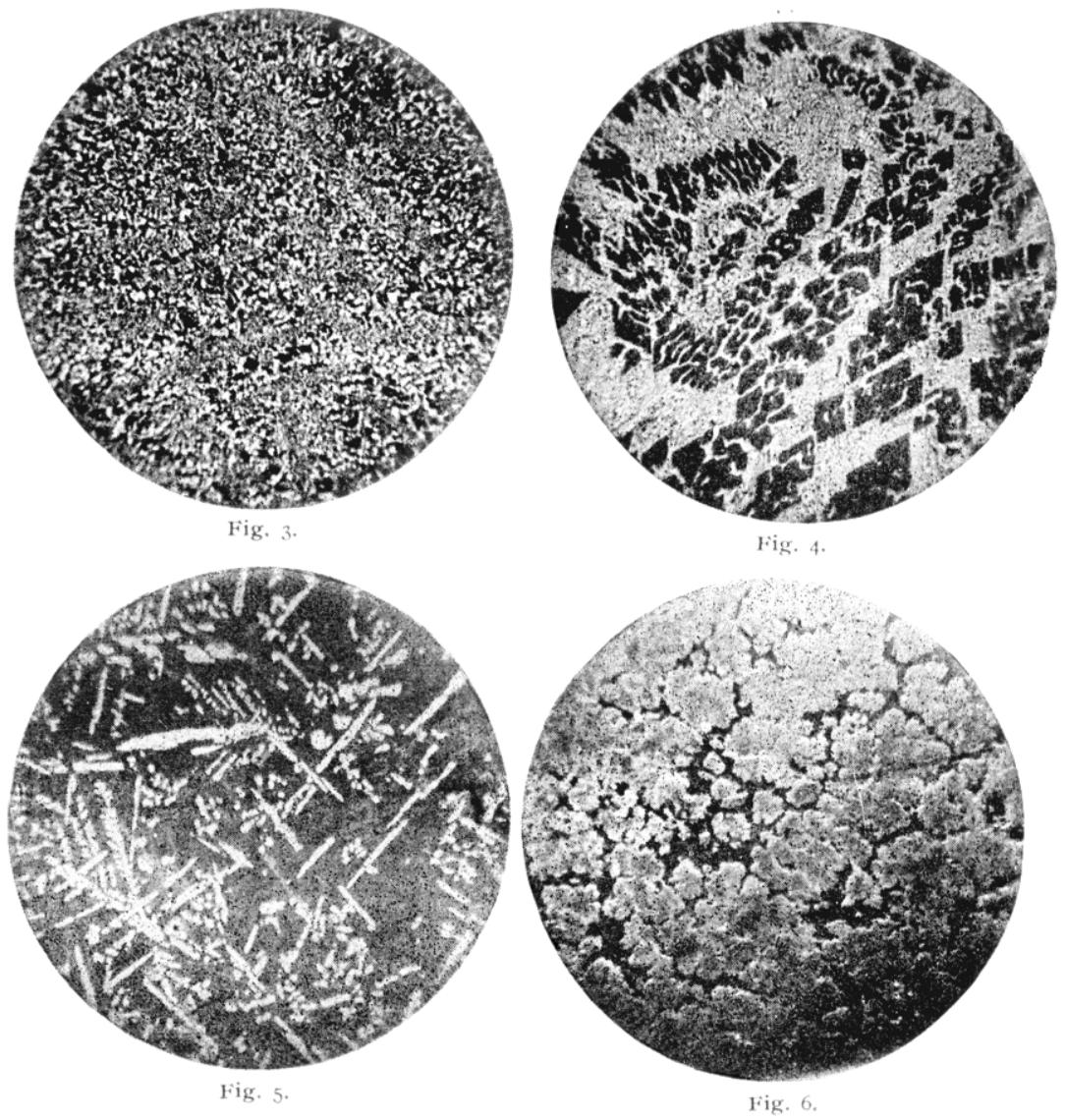

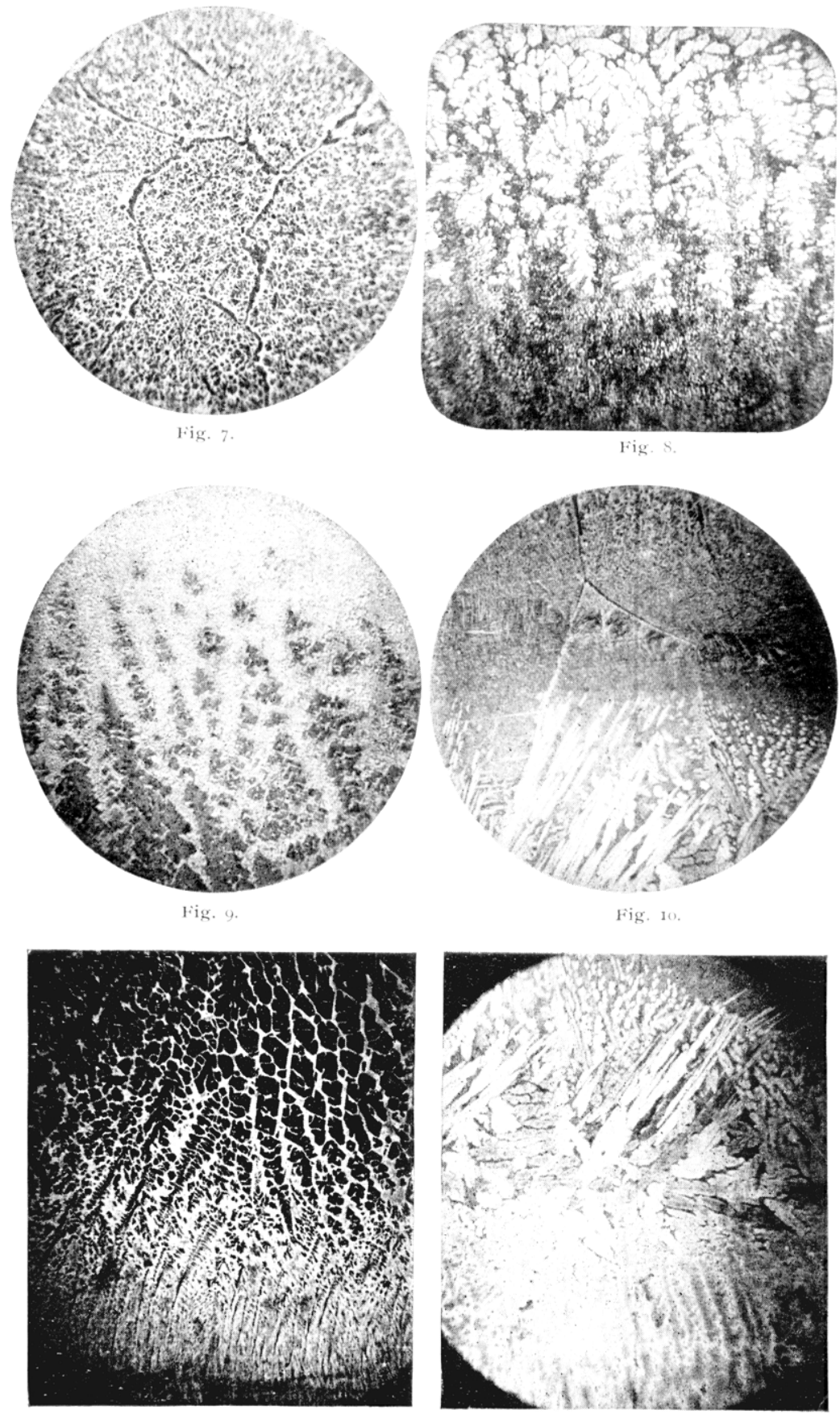

Fig. 11.

fig. 12 


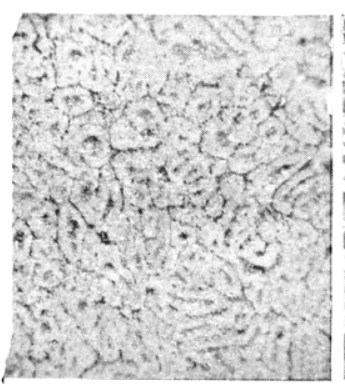

Fig. 13 .

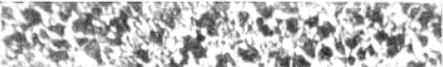

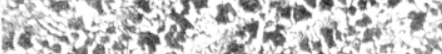

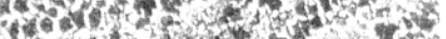

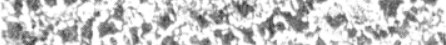
6.

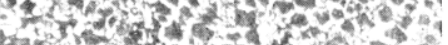

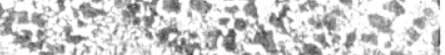

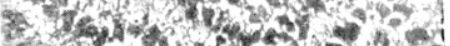

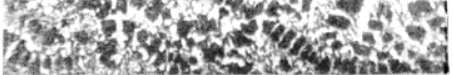
Fig. 14.

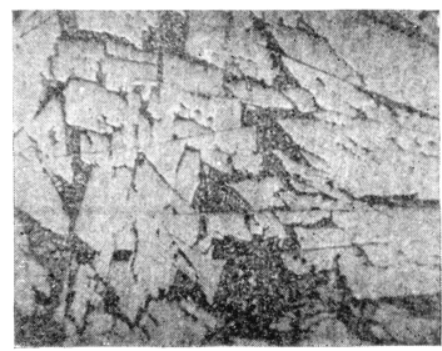

Fig. I7.

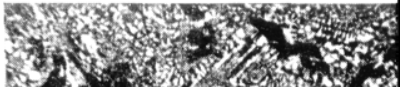

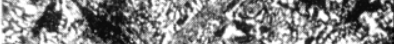

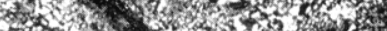

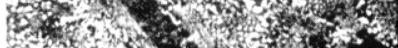

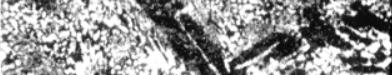

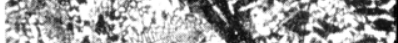

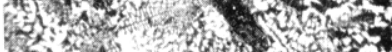

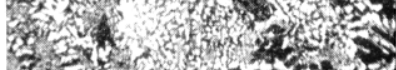

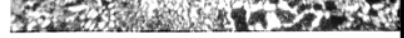

Fig. 15 .

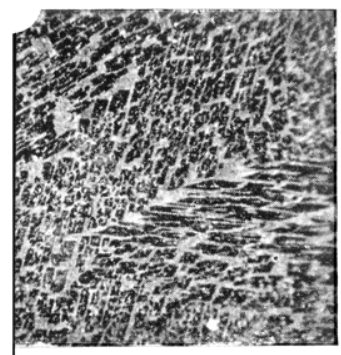

Fig. 16.

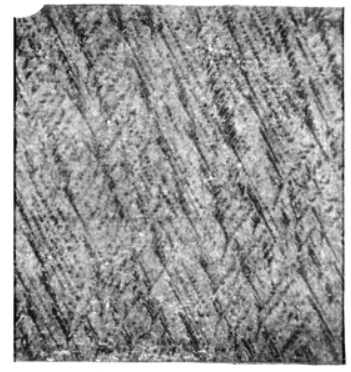

Fig. I9.

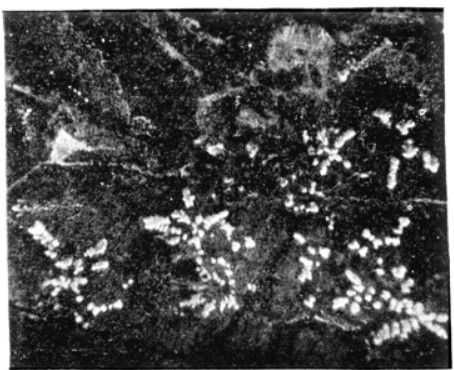

Fig. 20.

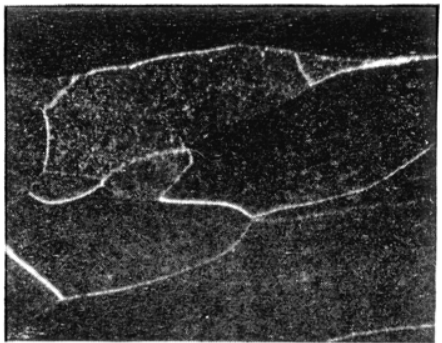

Fig. 23 .

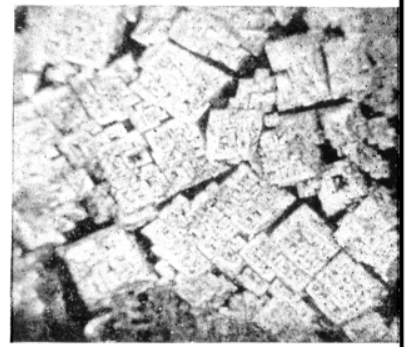

Fig. 18 .

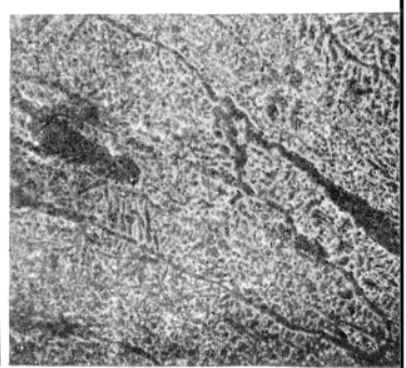

Fig. 21.

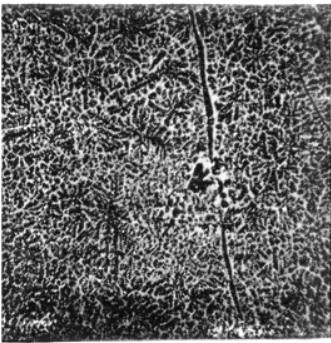

Fig. 22.

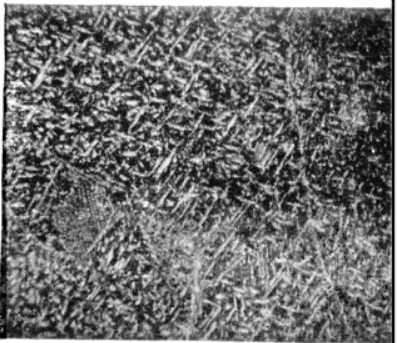

Fig. 24 


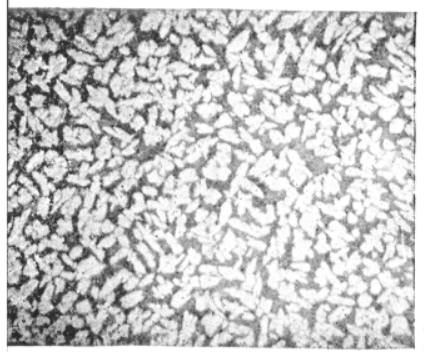

Fig. 25.

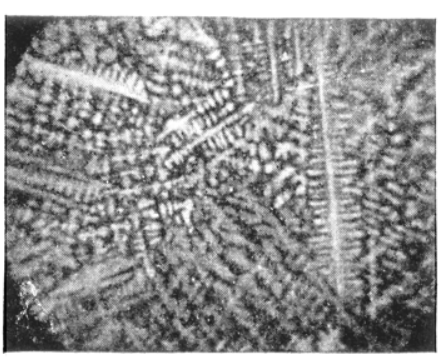

Fig. 26 .

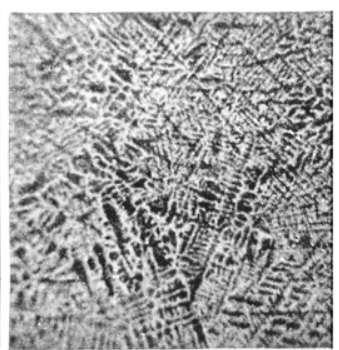

Fig. 27.

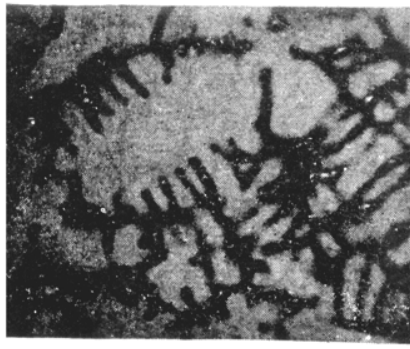

Fig. 28 .

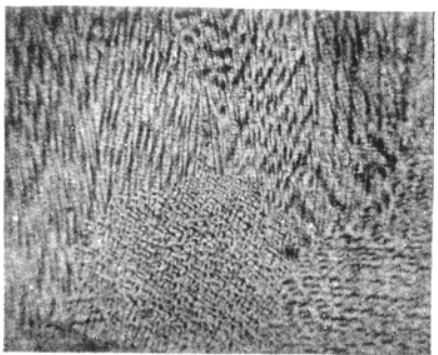

Fig. 29.

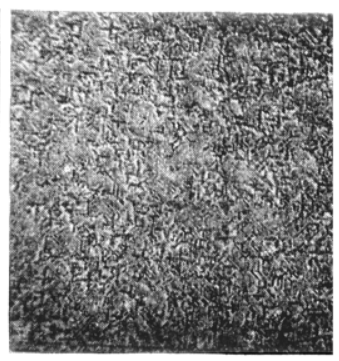

Fig. 30

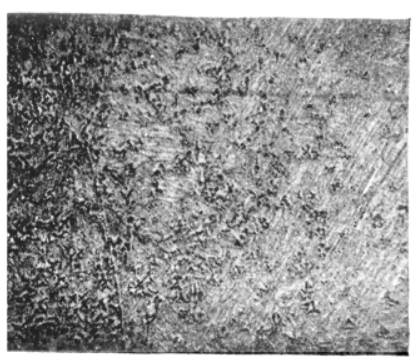

Fig.' 3 I.

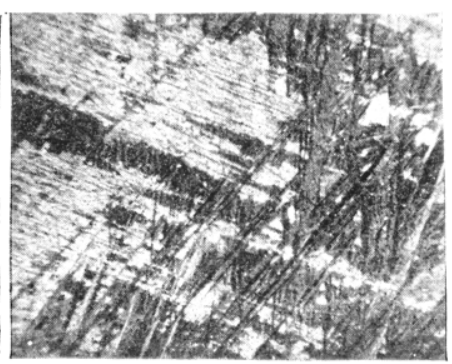

Fig. 32.

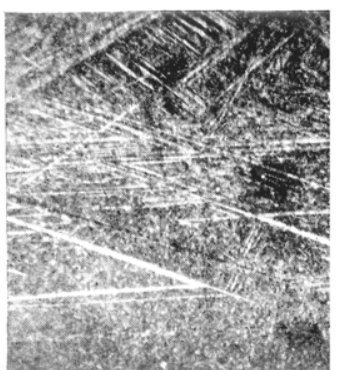

Fig. 33 .

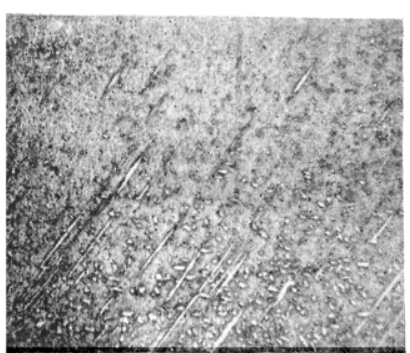

Fig. 34 .

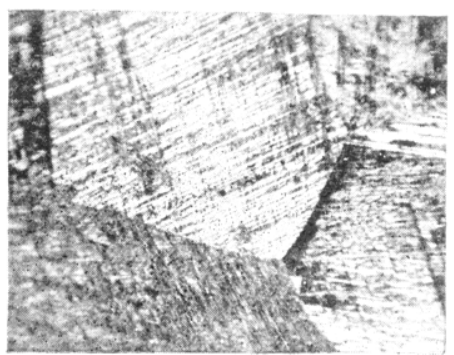

Fig. 35 .

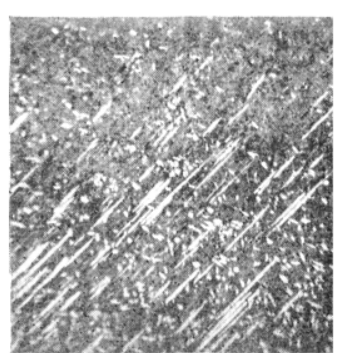

Fig. 36 . 
eutectic shows almost dendritic aluminium in places, also black lines, but these are smaller than in the 32 per cent. alloy. When cast, is hard and brittle, with a coarsely crystalline bright fracture, which shows prisms under the microscope. A section shows the compound in parallel groups of short prisms, similarly orientated in each group, giving a very decided ingot structure. Groundmass in places, composed of aluminium alone where the crystals of the compound are closely packed. Fig. 4 shows the alloy slowly cooled, $\times 30$ o., while Fig. I 6 shows the same when cast, $\times 33 \circ$. Three separate groups of the black prisms are seen surrounded by a ground-mass of the eutectic.

47 per cent. $\mathrm{Cu}, 5.3$ per cent. Al. A very coarse, whitish fracture, with large shining faces. In sections the compound is seen in prisms, which now interfere and are surrounded by the eutectic, as before. The cast alloy shows a bright crystalline fracture with well-marked ingot structure, due to the prisms. Fig. 17, $X 30 \mathrm{v}$, shows the slowly cooled alloy, lightly etched. In addition to the compound and the eutectic, long needles are seen. These are not attacked after long etching and are probably the silicide of copper and aluminium found by Guillet. They were noticed in small quantity in many of the alloys containing $\mathrm{Al}_{2} \mathrm{Cu}$.

5 I per cent. $\mathrm{Cu}, 49$ per cent. Al. Has a beautiful shining fracture, showing, in places, very large and long prisms in parallel groups. A longitudinal section of one of these shows very little eutectic, which lies as a cement between the massed prisms. When cast, the alloy forms a bright ingot with a glistening whitish fracture, which is coarse and shows prisms. The surface structure of the ingot is composed of the basal planes of these prisms, which stand in relief owing to the shrinkage of the liquid portion on cooling. The structure resembles that of bismuth. In sections the massed prisms of the compound are found to be similarly orientated and there is very little ground-mass between them, showing that we have almost reached a homogeneous alloy. The prisms etch much deeper in the center than at the outside, which seems to point to their containing some aluminium in solid solution. Fig. I8, $X$ I6 v., shows the surface structure of an ingot, with the prisms standing out in relief.

54 per cent. $\mathrm{Cu}, 46$ per cent. Al. Hard brittle alloy with a fracture similar to the last, but more hackly; shows some prisms in cavities. In sections we find the massive compound, which is evidently built up of massed prisms, whose boundaries show out as lines. At the base of the alloy a section showed a few bright white grains and dendrites, evidently the first appearance of a new constituent. The ingot is brittle with a hackly fracture. Fig. 20, $\times 35$ v., shows the slowly cooled alloy deeply etched with dilute nitric acid, which has blackened the compound $\mathrm{CuAl}_{2}$, but left the bright white dendrites unattacked. Under a higher power numerous fine white dots can also be seen, similar to the dendrites. 
From 54 per cent. copper onwards, the freezing-point curve consists of a very steep rise to a summit at about 90 per cent. copper at I055 $5^{\circ}$. There are several marked subsidiary points, but these were so slight that no definite conclusions could be drawn from them. The compound $\mathrm{AlCu}_{3}$ is indicated by the summit ( 87.6 per cent. copper) and has been isolated by Le Chatelier. It remained for the microscope to determine the constitution of the intermediate alloys, and by its means the following results were obtained:

As the copper is increased above 54 per cent. the fine white dendrites grow larger and become more numerous. They swell ont and become large, extended grains, while the ground-mass of $\mathrm{Al}_{2} \mathrm{Cu}$ decreases. At 70 per cent. copper there is still a comparatively large amount of ground-mass, but $\mathrm{AlCu}$, isolated by Guillet, contains 70 per cent. copper, which seems to point to the fact that we are dealing with a series similar to the SbSn series, in which Stead ${ }^{1}$ found that between 7.5 and 40 per cent. antimony, cubes of SbSn crystallize out in a ground-mass of tin containing antimony in solid solution. Above 40 per cent. antimony the cubes no longer are pure $S b S n$, but are richer in antimony, and the alloy corresponding to $\operatorname{SbSn}$ (i. c., 50.2I per cent. antimony) consists of crystals + ground-mass.

At 75 per cent. copper and 25 per cent. aluminium there is stil! a trace of the matrix, the color of the series having changed from white to a steely blue. From 78 to 83 per cent. copper, or from $\mathrm{Al}_{2} \mathrm{Cu}_{3}$ to $\mathrm{AlCu}_{2}$, the alloys are homogeneous, become more reddish in tinge and tend towards a glassy conchoidal fracture. Hence we might say that between these limits we have solid solutions of either of these compounds and that below, say 70 per cent. copper, the compound isolated, corresponding to $\mathrm{AlCu}$, was really $\mathrm{Al}_{2} \mathrm{Cu}_{3}$ or $\mathrm{AlCu}_{2}$, containing a fixed amount of $\mathrm{Al}_{2} \mathrm{Cu}$ in solid solution. The fact remains that the alloy corresponding to $\mathrm{AlC1}$ is not homogeneous.

57 per cent. $\mathrm{Cu}, 43$ per cent. Al. Still shows a whitish hackly fracture. A section shows narrow white bands and dendrites in a dark structureless ground-mass when etched with nitric acid. Without etching, the ground-mass has a slightly lighter color than the clendrites which are inclosed in it. Fig. $5, \times 33$ v., shows the slowly cooled alloy etched with nitric acid.

65 per cent. Ci1, 35 per cent. Al. Has a hackly fracture of a larker shade than the above. Under the microscope a mass of irregular cloud-like rosettes and a few stray dendrites are seen in the darker etching ground-mass. The cast alloy is brittle, with a bluish gray color and is composed of clasely packed rough dendrites in parallel groups set in the darker etching ground-mass.

67 per cent. Cu, 33 per cent. Al. Similar alloy of bluish gray color. Is hard and brittle, with a tendency to sub-conchoidal fracture. By polishing alone the alloy is seen to be composed of

$1 \mathrm{~J}$. Soc. Chem. Ind., is $97, \mathrm{pp}, 200$ and 506. 
bluish tinged cloud-like grains, surrounded by a yellowish white ground-mass $\left(\mathrm{Al}_{2} \mathrm{Cu}\right)$. The ground-mass is much softer than the grains, which polish in relief. On etching with nitric acid the ground-mass turns brown to black, while the grains are attacked, but not evenly. The cast alloy is hard, with a sub-conchoidal fracture. The surface shows very small feathery dendrites of hexagonal type in relief. In sections we have a similar structure to the slowly cooled, but, of course, much finer. The grains oxidize in the atmosphere much more than the ground-mass. Fig. $6, \times 33$ v., shows the slowly cooled alloy, etched with nitric acid and gives the characteristic structure of the cloud-like grains.

70 per cent. $\mathrm{Ct1}, 30$ per cent. Al. Bluish gray, with a fracture similar to the last. On polishing, the alloy shows the same bluish grains surrounded by the lighter matrix. On etching, the groundmass turns brown to black, as before. Under oblique light the dendrites appear white, for they have been attacked, while the ground-mass is a dead-black. The only difference between the two alloys is that here we have less of the ground-mass $\left(\mathrm{Al}_{2} \mathrm{Cu}\right)$, as we should expect. The cast alloy is also similar and shows irregular grains surrounded by an envelope of the lower compound. The grains etch before the ground-mass, which blackens only. Hence we see that the alloy corresponding to the formula $\mathrm{CuAl}$ is composed of two constituents.

75 per cent. $\mathrm{Cu}, 25$ per cent. Al. Very brittle, of a bluish tinge. When etched with nitric acid and examined under a low power it is seen to be coarsely crystalline, like a compound or a pure metal. Under a high power the last traces of the white constituent, or ground-mass, are seen filling a few isolated interspaces between the grains. Many of the grains have a banded structure, like twinning or that due to strain in some metals. The surface, when deeply attacked, shows innumerable small negative crystallites, more or less lath-shaped.

80 per cent. $\mathrm{Cu}, 20$ per cent. Al. Very hard, brittle, of a reddish tinge. Only one constituent can be seen; even when deeply etched the alloy appears homogeneous. When cast the alloy shows a very coarse ingot structure, but there is no second constituent. The alloy resembles $\mathrm{SnCu}_{3}$.

83.26 per cent. $\mathrm{Cu}, \mathrm{I} 6.74$ per cent. A1. Very hard, of a distinctly reddish tinge, coarsely crystalline, each grain etching out with dotted lines as boundaries and being built up of secondary grains. When cast, has a bright, glassy, almost conchoidal fracture, with reddish tinge. A section shows good ingot structure on etching, with dotted lines showing up the borders of the primary grains, which, under a high power, are built up of fine secondaries. No second constituent can be seen, though its beginning is indicated by the etching of the boundaries of the grains. 
From this point, corresponding to $\mathrm{AlCu}_{2}$ onwards, the alloys are very complicated. According to Le Chatelier the fusibility curve consists of a continued rise to a summit at $\mathrm{AlCu}_{3}$, followed by a slight fall to a minimum at 90 per cent. copper ancl then a uniform rise to the melting-point of pure copper. Our own curve is similar in shape. The meaning of the fall is uncertain and when the evidence of the microscope is considered it seems probable that we ought to have a smooth curve from 83 per cent. copper to pure copper, or at all events two curves which make an obttise angle and show no fall. As in our curve, this fall is only from $15^{\circ}$ to $20^{\circ} \mathrm{C}$., it may have been caused by surfusion. The microscope and heat treatment show that between 83 per cent. and about go per cent. copper the alloys solidify as homogeneous solicl solutions, which, at a lower temperature, rearrange themselves in a manner directly comparable to steel or the coppertin alloys from $\mathrm{Cu}_{4} \mathrm{Sn}$ onwards. The eutectoid point is about 87 por cent. copper, as compared with pearlite with 0.8 per cent. carbon, or the copper-tin entectoicl at 75 per cent. copper. The slowly cooled alloys between 84 per cent. copper and 87 per cont. copper consists of decreasing amounts of a compound poorer in copper (probably $\mathrm{A} / \mathrm{Cu}_{12}$ ); those between 87 per cent. and about 90 per cent. copper consist of increasing amounts of a compound richer in copper (which Le Chatelier found to be $\mathrm{AlCu}_{3}$ ), set in the eutectoid. On reheating any of these alloys to a bright red and quenching, a structure is produced similar to martensite of quenched steel, while by annealing the quenched alloy for a short time the original structure is restored. The complete cooling curve for the series must, therefore, show a Y-shaped curve between 83 and go per cent. copper at some distance below the "soliclus," and similar to that clenoting the senaration of ferrite and cementite in steel, or of $\mathrm{SnCu}_{4}$ in the copper-tin alloys. On account of its steepness it is probable that it will only be determined by clifferential cooling curves.

From go per cent. copper onwards the color of the alloys changes from yellow to red with a corresponding change in structure as the dendrites of copper come in, the alloys being solid solutions.

85 per cent. $\mathrm{Cu}$, ${ }_{5} 5$ per cent. Al. Shows a marked change in color to a recllish straw. Fracture sub-columnar. A section shows two constituents; large granular structure (Fig. $7, X$ I6 v. etched by nitric acicl), each grain being bounded by black veins and filled with black irregular rosettes and dendrites, surrounded by a white ground-mass. The structure is very similar to that of a 70 per cent. copper ancl 30 per cent. tin alloy. The cast alloy is brittle, with a glassy fracture. Shows an ingot structure and or etching is seen to be composed of the black compound and light ground-mass, like the slowly cooled alloy. Fig. $2 \mathrm{I}, \times 33$ v., shows the structure of the cast alloy. Under a high power in each case the grouncl-mass has a eutectoid structure, with a marked segre. 
gation of the light constituent on the borders. On reheating to a bright red and quenching, the original structure is destroyed, and under low powers the alloy appears homogeneous, while by reheating again and slowly cooling, a structure similar to the original is reproduced. Fig. $22, \times 35$ v., shows the alloy after quenching, reheating and slowly cooling in the air. The structure is now even clearer than the original. Now, seeing that these changes took place far below the melting-point of the alloy, they must be changes in the solid, and the ground-mass is, therefore, not a eutectic, but a eutectoid like pearlite.

87 per cent. Cu, I3 per cent. Al. Eutectoid, and therefore consists entirely of the ground-mass, whose composite structure can only be seen under high powers. On reheating and quenching it assumes a structure resembling martensite, while annealing restores the original.

88.5 per cent. Cu, II.5 per cent. Al. Decidedly yellow color. A crack showed dendritic structure, due to the original cooling of the solid solution. On etching a section, the ground-mass or eutectoid is attacked, leaving light yellow needles and fine grains in relief. The ground-mass has a comparatively coarse granular structure, whose boundaries are shown by the marked orientation of the yellow needles. Fig. 24, $\times 33$ v., shows this alloy. Le Chatelier found the yellow needles to be $\mathrm{AlCu}_{3}(87.6$ per cent. copper), but they evidently contain more copper than this, for they must contain more copper than the whole alloy. The cast alloy shows a splendid columnar structure when broken. It is very tough and cuts well. In section the columnar structure is explained, for the alloy is built up of long grains or columns perpendicular to the cooling faces. Each grain has a lighter border, due to the segregation of needles of the compound from the solid solution. Fig. $23, \times 33$ v., shows the cast alloy, in which cooling was too rapid to allow the solid solution to completely rearrange itself into the yellow constituent and the eutectoid. If the alloy be reheated to a bright red and quenched, a structure like martensite is produced as before, while annealing restores the original, showing the original was due to change in the solid.

89.5 per cent. Cu. Io.5 per cent. Al. A similar alloy in appearance, fracture, etc. A section shows the effect of the slight increase in copper by the increase in size and quantity of the yellow constituent. Fig. $25, \times 35 \mathrm{~V}$, shows the slowly cooled alloy. It is composed of lighter grains in a darker groundmass, which is the eutectoid. There is a marked contrast when compared with the last alloy. When cast, the structure of the alloy depends entirely on the thickness of the ingot, or rather on the rate of cooling. In no case was a structure like Fig. 23 found. Where the ingot was thin, its structure $X$ Io is represented by Fig. 24, while a thicker ingot would show a structure similar to this, but much coarser. Again, when quench- 
ing the alloy to produce the martensitic structure, it is necessary to heat this alloy to a higher temperature than that required by the last (just as the refining temperature of a 0.35 per cent. carbon steel is much higher than that of steel with 0.75 per cent. carbon), because the yellow granular constituents begin to separate out at a much higher temperature.

9I per cent. $\mathrm{Cu}, 9$ per cent. Al. Hard, tough, light yellow, very strong. When a section is etched, it is seen without using a lens to be built up of grains or crystals, each of which in turn is built up of dendrites whose orientation varies from grain to grain Under the microscope a discontinuous ground-mass is seen, but is in very small amount, and even under high powers has no distinct structure. The dendrites, on the other hand, are not uniform in composition, for they etch at the center, or core, to a darker color than at the ontside. In other words, they are richer in copper at the center, due to diffusion not being sufficient to produce a state of equilibrium. In all cases so far the copper-rich cores have made their appearance before the ground-mass has disappeared, which shows that we are lealing with solic solutions and not a pure compound, $\mathrm{AlCu}_{3}$. When cast, the alloy is hard and yellow, with a fine columnar fracture. A section shows that this is due to casting, for each elongated grain or crystal is built up of dendrites like those of the slowly cooled alloy, but very much finer: the grouncl-mass is discontintious as before.

94 per cent. Cu. 6 per cent. 11. Very tough, golden yellow, of a very coarse structure, which can he seen by the eye on etching. It is built up of huge dentrites like copper, etching differentially ( $i$. o. deener in the centers, or cores, and progressively less to the outside), which shows we are dealing with solid soltitions whose compositions vary uniformly from edge to center of the dendrites, becoming richer in conper. The ground-mass seen in the a per cent. conner alloy has gone, the whole mass being built up of clendrites isomorphons with copper. Fig. $26, \times$ I 50 . shows the alloy, etched with hydrochloric acid. If ammonium hydroxide be used, the structure is shown up hy a beautiful series of colors, similar to those produced by heat-tinting. The cores are most deeply colored: brown, red and violet; the edges are green, straw and white.

06.3 per cent. Cu, 3.7 per cent. Al. Hard, tough, darker yellow, shows a splendid dendritic structure to the eye when etched, like the $9 t$ per cent. alloy. The whole structure is very coarse. There is no second constituent, but differential etching shows that we have a solid solution which is not in equilibrium. When cast the structure is similar, but smaller, and is built up of dendrites definitely arranged, Fig $27 . \times 16$ v., shows a vertical section through a small ingot. The difference in shade between the centers and boundaries of the dendrites is marked. Their cubic character resembles that of copper. 
97. I per cent. $\mathrm{Cu}, 2.9$ per cent. Al. Tough, reddish yellow, huge grains and dendrites, which etch very differentially. Fig. 28, $\times 33$ o., shows the typical structure on etching with hydrochloric acid. Cast alloy is strong and tough, with a reddish columnar fracture. A section shows a structure similar to the last alloy, but with the dendrites less pronounced and the grantlar structure more marked, owing to the better orientation, as is shown in Fig. 29, $X I 6$ v.

A further increase in copper gives similar alloys until at 100 per cent. we have the structure of pure copper. In dealing with the series from about 92 per cent. copper onwards acid of a considerable strength is necessary to bring out the structure of these solid solutions. Hydrochloric acid blackens the cores and leaves the edges of the dendrites bright. Nitric acid attacks the edges most, the cores next and the intermediate zone least of all. Ammonium hydroxide produces beautiful oxidation tints, which show the cores dark and the edges light.

DIFFUSION ALLOYS.

In order to make sure that no important change had been overlooked and to confirm previous results, ten or more diffusion alloys were made by pouring molten aluminium on to molten copper or a molten aluminium-rich alloy on to one containing more copper and allowing the whole to slowly solidify, thus obtaining by diffusion an alloy which varied uniformly in composition from top to bottom.

o to 52 per cent. $\mathrm{Cu}$. At the top the alloy shows massed grains of aluminium. On passing downwards the eutectic appears and increases; the aluminium grains become smaller, change to dendrites and finally disappear at the eutectic ratio, 32 per cent. $\mathrm{Cu}$, 68 per cent. Al. Fig. $8, \times 35$ v., etched with dilute nitric acid shows this section. Below this point crystals of the compound $\left(\mathrm{Al}_{2} \mathrm{Cu}\right)$ come in and increase as the eutectic decreases, until at about 52 per cent. copper, the whole mass is composed of the compound. Fig. $9, \times 35$ v., etched with dilute nitric acid, shows this change in structure. Two points were noticed: The eutectic area forms a broad band across the alloy and if the alloy varies uniformly in composition it would seem to show that the eutectic could vary in composition within certain small limits. Again, at the aluminium end, the eutectic shows a relatively large amount of the compound, while at the lower (copper aluminium) end it shows a relatively greater amount of aluminium. This is due to absorption of aluminium by aluminium dendrites and of $\mathrm{Al}_{2} \mathrm{Cu}$ by the crystals of the compound. A similar thing happens in the $\mathrm{AgCu}$ series and other alloys.

54 to 80 per cent. $\mathrm{Cu}$. At the top of this range the alloy is homogeneous and very brittle, being composed of $\mathrm{Al}_{2} \mathrm{Cu}$. As 
we pass down, grains and rods of the new constituent come in and increase with the copper content. The ground-mass of $\mathrm{Al}_{2} \mathrm{Cu}$ decreases, the grains, etc., become dendrites, which change to cloud-like masses, while finally at the base of the series the whole mass is homogeneous once more.

80 to IOO per cent. Cu. Starting at the top of this range we have a homogeneous mass as at the base of the last. Etching with nitric acid as before, or with hydrochloric acid, shows this black. Passing down, a whitish ground-mass soon appears and surrounds the black crystals, which have definite boundaries. The ground-mass under high powers shows the composite structure of a eutectoid. The eutectoid increases, the black crystals decrease and become very fine dendrites and finally clisappear when the whole mass is composed of the eutectoid at about 87 per cent. copper. Fig. I I, X 35, etched with clilute hydrochloric acid, shows this range, while the top of Fig. 1o, $\times 33$ v., shows the disappearance of the black clendrites. The eutectoid occupies a distinct band across the alloy and has a more or less linear structure in its central portion. Lelow this, bright yellowish needles of the higher compound come in. These increase in size and quantity, and the etutectoid diminishes, as is shown in the lower part of Fig. 10, $\times 33$ v., etched with hyclrochloric acid. Before the ground-mass entirely disappears it loses its eutectoid structure and in the center of the yellow grains dark etching cores appear. These increase and the ground-mass finally disappears. The change is shown in Fig. 12, $\times 33$ v., etched with hydrochloric acicl. This brings us to about 92 per cent. copper and from this point onwards the cores, rich in copper, increase in size and quantity till the mass becomes pure grains and dendrites of copper at 100 per cent. The change undoubtedly represents a series of solid solutions.

\section{IJFAT TREATAENT AND CHANGE OF STRUCTURE IN THE SOLID.}

To show the changes round the ettectoid point a diffusion alloy ranging from 85 to 89 per cent. copper was made and very slowly cooled. At the top, dark etching crystals and dendrites were seen, surrounded by the eutectoid with a fine structure. These diminish and clisappear near the center of the section, while the eutectoid assumes a very coarse structure (comparatively). Below this point needles and grains of the yellow constituent appear and increase. while the ground-mass assumes a finer, mottled structure. Fig. 30 shows the section near the top, with the dark dendrites set in the entectoid. Fig. 3 I is between the top and center, showing the disappearance of the black dendrites and the coarsening of the ground-mass, while Fig. 34 shows the section near the base, with the bright yellow needles and grains. In each case the magnification is $35 \mathrm{v}$, etched with ammonitum hydroxicle. The alloy was heated to a bright red and quenched. The original 
structure was destroyed and a new one, resembling that of martensite of quenched steel, produced. Fig. $32, \times 35$ o., shows the structure of the quenched specimen from the top to the center, while Fig. 35, $\times 35$ o., shows that near the base where very coarse polygons have developed, similar to those of martensite in much overheated and quenched steel. This shows that at the high temperature the whole series exists as a uniform solid solution, like martensite or the copper-tin alloys, ${ }^{1}$ which have been so well worked out by Heycock and Neville. On reheating the quenched alloy to a bright red and cooling in the air the martensitic structure was, for the most part, destroyed and the original almost completely restored. At the top of the section black dendrites make their appearance and the appearance is similar to Fig. 3I, but the whole structure is coarser. The center of the alloy shows a beautiful martensitic structure still, but it is much finer than that of the quenched specimen. Fig. $33, \times 35$ v., shows this new structure. At the base the original structure has been completely restored, as seen in Fig. $36, \times 35$ v. The reason why the central band of the entectoid retained the martensitic structure on reheating was due to the fact that the cooling in air was too rapid to allow of complete change. A second reheating, followed by slow cooling in the furnace, removed all trace of it. A similar alloy was made, but was reheated to the melting-point and allowed to cool slowly in the furnace. In this way the range of composition varied from top to bottom from $86+$ per cent. to 88.5 per cent. copper, or a little over 2 per cent. A section showed a coarse granular structure (polygonal grains) to the eye. At the top of the alloy a few black dendrites (like Fig. 3I) were seen, but soon disappeared. The eutectoid occupied a comparatively broad band just above the center of the alloy, below which bright, thin needles, then grains of the yellow compound came in. At the base the structure was like Fig. 34 . On reheating and quenching at a bright red, the whole mass became martensitic, exactly like the last alloy, while the base of the alloy showed a coarse granular structure, as before. On reheating and slowly cooling in the furnace the original structure was restored, the coarse grains due to the original cooling being even more marked, due to segregation around their boundaries. No sharp change in the eltectoid structure was met with, but, as before, it was noticed that, where neither of the constituents were present in the free state, the structure was most coarse. Both of these experiments show that between about 83 and 90 per cent. copper there are profound changes in structure, which take place in cooling, far below the "solidus."

The above work points to the following conclusions:

(I) The series between 0 and 54 per cent. copper forms a simple set of alloys with a eutectic point at about 32 per cent. copper.

I Phil. Trans. Roy, Soc. (1,ondon), A. 202, I-69. 
Between $O$ and 32 per cent. copper, grains and dendrites of aluminium occur in an increasing ground-mass; between 32 and 54 per cent. copper, crystals of the compound $\mathrm{Al}_{2} \mathrm{Cn}$ occur in a decreasing ground-mass of the eutectic. In neither case are the dendrites or crystals pure but contain about 2 per cent. of copper, ${ }^{1}$ or of aluminium, as the case may be, in solid solution.

(2) From 54 per cent. copper onwards we find a decreasing ground-mass of $\mathrm{Al}_{2} \mathrm{Cu}$, while a new constituent, in the form of dendrites and then irregular masses, increases until at about 78 per cent. copper the alloys are homogeneous.

(3) The alloys remain homogeneous from 78 per cent. to about 83 per cent. copper (from $\mathrm{Al}_{2} \mathrm{Cu}_{3}$ to $\mathrm{AlCu}{ }_{2}$ ).

(4) It is open to question whether this new constituent is $\mathrm{AlCu}, \mathrm{Al}_{2} \mathrm{Cu}_{3}$ or $\mathrm{AlCu}_{2}$, for in any case it forms solid solutions. There may even be two isomorphous compounds present.

(5) Above 83 per cent. to about 90 per cent. copper the allovs solidify as solid solutions, which, at a lower temperature, rearrange themselves, according as the alloy contains more or less than 87 per cent. copper-the eutectord point. This change is similar to that which takes place in steel or in the bronzes.

(6) From 92 per cent. to Ioo per cent. copper, the alloys form a series of solid solutions isomorphous with copper and show no rearrangement in the solid state.

In conclusion, my thanks are due to M. N. Bolles, Ph.D., who made several electrolytic copper determinations; to Professor Howe, in whose laboratory the work was carried out; and to Professor E. H. Miller, for his interest in the work.

DEPARTMENT OF METALLTRGY.

COLUMBIA UNIVERSITY.

\title{
ON THE STRUCTURE OF ALLOYS. PART II. SOME TER- NARY ALLOYS OF TIN AND ANTIMONY."
}

\author{
BY WILLIAM CAMPBELL.
}

Received July :, roos.

THE alloys of tin and antimony have been studied by Stead, ${ }^{3}$ Behrens, ${ }^{4}$ Reinders, ${ }^{5}$ and others. Between $O$ and 7.5 per cent. of

1 This would probably be in solution as $\mathrm{Al}_{2} \mathrm{Cu}$.

2 Read before the New York Section of the American Chemical Society, June I0, 1904.

3 J. Soc. Chem. Ind., March-June, 1897 ; December, I898.

4 Versiagen d. Kon. Acad. v. Wetensch. te. Amst., June 25, I898, 59; and Baumaterialkunde, Vol. IV, Part 6 and 7 (Metallographist, Vol. III, p. 4).

i $Z$ tscht. astorg. Chem. 25, i13 (1900). 